\title{
There is more to chat discourse than written conversation
}

Cláudia Silva

Centre of Linguistics of University of Porto, Portugal

https://doi.org/10.36505/ExLing-2010/03/0042/000162

\begin{abstract}
In this paper, we aim at comparing some deviations from standard writing present in Portuguese and English informal chats in order to reflect on the linguistic knowledge that lies beneath these innovative spellings: phonetic, phonological or orthographic.
\end{abstract}

Key words: chats, spelling, deviations, phonetic and phonological knowledge

\section{Introduction}

In this study, we intend to analyse chat discourse in Portuguese and English to verify whether this type of text is merely a conversation which is reproduced in written form or whether it can reveal the speakers' linguistic knowledge.

It is generally agreed that the barriers between oral speech and writing are attenuated in chat discourse, a type of online synchronous communication which is often designated as written conversation (Crystal 2001).

In fact, as communication develops in real time, there is the need to write quickly in order to accompany the rhythm of the interaction. Consequently, chatters use some mechanisms in order to make writing more informal and closer to oral speech. These mechanisms include elision of letters which represent silent sounds, change of grapheme to reproduce the sounds actually heard, repetition of graphemes to suggest the lengthening of vowels or consonants typical of oral speech, absence of capital letters or punctuation marks, which are writing conventions, and use of paralinguistic elements to show emphasis or the attitudes and feelings of chatters. This suggests the relevance of phonetics to chat discourse.

However, it is our belief that chat discourse can reveal more about the speakers' knowledge than their ability to accurately reproduce the pronunciation of words. In Portuguese, at the phonetic level, the deletion of schwa creates sequences of up to five consonants, which highly exceed the two generally accepted as onset for this language (Mateus \& Andrade 1998). We could thus say that European Portuguese syllable structure is more complex at the phonetic level, and this could make it closer to syllable structure in English (cf. Hammond 1999), which admits sequences of three or four consonants in word-initial or final position,

ExLing 2010: Proceedings of 3rd Tutorial and Research Workshop on Experimental Linguistics, 25-27 August, Athens, Greece 
respectively (even though it is believed that the excessive consonants are extrasyllabic). In fact, it should be noted that both Portuguese and English are described as possessing a stress-timed rhythm, and, consequently, they both present features like the use of schwas and the compression of unstressed syllables (for overview, see Migliori 2007).

Thus, as chat discourse is said to reproduce oral speech, we could presuppose that the same type of deviations would prevail both in European Portuguese and English, aiming at reproducing the phonetic forms of words.

Therefore, to verify if chat users are really being influenced by their phonetic knowledge, or rather by their phonological and even orthographic knowledge, we are conducting a corpora-based study, which is described below.

\section{Corpus-based study}

Sessions of both Portuguese and English chats were recorded. Concerning Portuguese, the chat sessions were taken from "bláblá" (aeiou), whereas English chats belong to Chatterbox (UK). We intended to record sessions from chats used by native speakers in order to collect data that reflected the speakers' intuitions of their mother tongue.

These two types of chats share similar features although they also show some divergences, according to some of the parameters defined by Herring (2007). As far as the similarities are concerned, they both possess a casual tone, they allow the use of nicknames freely chosen by users, they have a system that posts messages in the order in which they are received and they do not possess an official group topic. Concerning the main differences, the Portuguese chat enables interaction to happen from many to many whereas Chatterbox enables one-to-many interaction. Moreover, although the Portuguese chat studied is composed of text only, the English one enables the use of colourful emoticons. However, we believe that these differences do not significantly interfere with the type of language used in both.

All the words were divided into categories according to the types of deviations to standard writing or even to the respect of the orthographic form. Some examples of the categories include:

representation of the sound: of letters ('u' to "you"), of numbers ('2' to "to"), of the pronunciation of words ('xeio' to "cheio - full; 'wat' to "what");

changes at the syllable level: suppression of the onset ("kes' to "queres" you want; 'ovely' to "lovely"); whole rime ("ctg' to "contigo" - with you; 'bldy' to "bloody"), nucleus ("tecls to "teclas - you write; 'gd' to "good") or coda ('goto' to "gosto" - I like; 'wi' to "with");

changes in sequences of words, namely junction of words ('pergunteit' to "perguntei-te: I asked you; 'infront' to "in front"). 
The results which we are going to present are only preliminary as this is an ongoing study. Consequently, we prefer to refer to general tendencies rather than to quantitative results.

With regard to phonetic knowledge, we can verify that, in Portuguese chats, there are some deviations from standard orthography that may reflect a trend towards the reproduction of pronunciation, such as change of grapheme to imitate the sounds produced, deletion of silent graphemes, junction of words and adding of graphemes in order to imitate the lengthening of sounds typical of oral speech. Likewise, English chatters make use of some strategies in order to (creatively) imitate sound, like the deletion of silent graphemes and sequences of graphemes, the junction of words, and the reproduction of the sound of numbers and letters, a shortening device which is absent in Portuguese chats. These phonetic strategies seem to be more productive in English than in Portuguese, and we consider that this may be due to the fact that English orthography is more opaque than Portuguese spelling. Therefore, seeing that orthographic knowledge does not reflect phonological representations in a transparent way, it may be often disregarded by chat users in English. Moreover, there are more monosyllables in English, which can be easily replaced by a letter or number homophone.

As far as syllable structure is concerned, it is possible to see that there are more changes affecting the constituents of this prosodic unit in Portuguese than in English. The tendency in Portuguese is to delete the whole rime and to maintain the onset represented. If the goal was only to reproduce the phonetic forms of words, the unit would not be the whole rime but only the schwas, which do not correspond to a phonetic realization. Inversely, schwas are not always deleted, especially in less frequent words. We share Bybee's (2001) conviction that frequency (repetition) leads to reduction of form and that it influences the storage and processing of linguistic forms, which can be why schwas are only deleted in more frequent words. Furthermore, there is a tendency towards syllable regularization in some cases, which implies turning a CCV or CVC syllable into the format CV (more unmarked and cross-linguistically frequent according to Blevins 1995). In English chats, however, the suppression of graphemes seem to affect more the ones which do not correspond to an actual pronunciation, thus not affecting the syllable constituents but only involving the words as visual units. Moreover, the fact that there is not a tendency towards the formation of a CV syllable format may suggest that phonological intuitions in English admit a more complex syllable structure as unmarked. In fact, Archangeli (1997) refers to the low position that the restriction "No Complex" possesses in English, within an Optimality Theory approach. We could presuppose, therefore, that intuitions and markedness may be language-particular. 
Concerning orthographic knowledge, we can verify that conventions are preserved in different manners. On the one hand, many words are written according to norm. Although many diacritics disappear, others are maintained or are replaced by a letter expressing that function. Some words in Portuguese are influenced by the speakers' orthographic knowledge since they are graphed with a letter that usually represents that sound but not in that context, which suggests that they are not accurately analysing sound but are rather being influenced by spelling.

To sum up, not only is the phonetic knowledge important to chat users, but also their phonological and orthographic knowledge. Consequently, it is our opinion that chats are not merely a form of conversation that happens to be written but that this type of text should rather be studied as a form of access to the speakers' linguistic knowledge.

\section{References}

Archangeli, D. 1997. Optimality Theory: An Introduction to Linguistics in the 1990s. In Archangeli, D., Langendoen, D. (eds.) 1997, Optimality Theory, 1-32. Oxford and Massachusetts, Blackwell Publishers.

Blevins, J. 1995. The Syllable in Phonological Theory. In Goldsmith, J. (ed.) 1995, The Handbook of Phonological Theory, 206-244. Cambridge (Mass.)/Oxford, Blackwell.

Bybee, J. 2001. Phonology and Language Use. Cambridge: Cambridge University Press.

Crystal, D. 2001. Language and the Internet. Cambridge: Cambridge University Press.

Hammond, M. 1999. The Phonology of English - A Prosodic Optimality-Theoretic Approach. Oxford: Oxford University Press.

Herring, S. 2007. A faceted classification scheme for computer-mediated discourse. Language@Internet, 4, article 1. Retrieved June 2, 2009, from http://www.languageatinternet.de.

Mateus, M., Andrade, E. 1998. The syllable structure in European Portuguese. In Mateus, M. 2002. A Face Exposta da Língua Portuguesa, 281-297. Lisboa, Casa da Moeda.

Migliorini, L. 2007. Ritmo Silábico/ Ritmo Acentual: Divergências quanto às definição de Ritmo do Português do Brasil. In Estudos Lingüisticos XXXVI vol. 1, 47-51. Retrieved April 5. 2010 from http://www.gel.org.br/estudoslinguisticos/. 